\title{
RAIINSTEK
}

\section{RANCANG BANGUN SISTEM INFORMASI REKOMENDASI ASURANSI KENDARAAN BERBASIS WEB PADA PT. ASURANSI TRI PAKARTA}

\author{
Ryan Yugi Affandi ${ }^{1}$, Hari Lugis Purwanto ${ }^{2}$, Kawakibul Qamar ${ }^{3}$ \\ Sistem Informasi, Universitas Kanjuruhan Malang ${ }^{1,2,3}$ \\ ryanyugiaffandi@gmail.com ${ }^{1}$, hari_lugis@unikama.ac.id ${ }^{2}$, ikings@ unikama.ac.id $^{3}$
}

\begin{abstract}
Abstrak. Sistem rekomendasi dirancang untuk membantu dalam pengambilan keputusan diawali dari mengidentifikasi masalah, memilih data yang relevan, menentukan cara pendekatan yang digunakan dalam tahapan proses pengambilan keputusan. Fokus dalam penelitian pengembangan ini mengacu pada pengembangan pendekatan waterfall. Jenis data dalam penulisan penelitian ini adalah jenis data kuantitatif, yaitu prosedur penelitian yang menghasilkan angka. Instrumen pengumpulan data dilakukan dengan wawancara secara terstruktur. Hasil yang disimpulkan dari penelitian pengembangan ini adalah dengan dikembangkannya sistem rekomendasi produk asuransi kendaraan memiliki acuan untuk memilih produk asuransi kendaraan yang didapat dari kriteria yang sudah ditentukan, sehingga kebijakan yang diambil oleh pengguna atau calon nasabah sesuai dengan kebutuhan.
\end{abstract}

Kata Kunci: Rekomendasi Asuransi, Sistem Informasi, Web

\section{PENDAHULUAN}

Pertumbuhan industri asuransi kendaraan di Indonesia berkembang pesat. Hal tersebut diungkapkan oleh Direktur Eksekutif Assosiasi Asuransi Umum Indonesia (AAUI) yang menyatakan pertumbuhan premi dari lini bisnis asuransi kendaraan meningkat di tahun 2018 hampir setara dengan asuransi properti (Dalimunthe, 2018).

Sebagian calon nasabah asuransi masih kurang yakin dalam memilih produk asuransi kendaraan karena banyaknya produk asuransi yang ditawarkan dan perluasannya, serta bahasa yang digunakan dalam asuransi adalah bahasa polis atau bahasa asuransi yang tidak mudah dimengerti oleh masyarakat umum. Selain itu calon nasabah lebih mudah terpengaruh oleh penawaran yang diberikan pihak marketing dari perusahaan jasa asuransi, pernyataan ini diungkapkan oleh pihak marketing PT. Asuransi Tri Pakarta cabang Malang. Hal tersebut menyebabkan produk jasa asuransi yang dipilih oleh nasabah tidak sesuai dengan kebutuhan nasabah.

Sistem informasi rekomendasi produk asuransi kendaraan ini dibuat untuk memudahkan calon nasabah asuransi dalam memilih produk asuransi kendaraan sesuai dengan kebutuhan calon nasabah asuransi kendaraan.

\section{METODE PENELITIAN}

\section{A. Waterfall}

Model pemgembangan waterfall merupakan proses pengembangan perangkat lunak secara berurutan dimana kemajuan terus mengalir ke bawah seperti air terjun melewati tahap tahapanya. Inti dari model waterfall adalah proses pengerjaan suatu sistem yang dilakukan secara berurutan atau secara linear (Kadir, 2003). Tahapan dalam model pengembangan waterfall dapat dilihat pada Gambar 1. 
1. Analisis

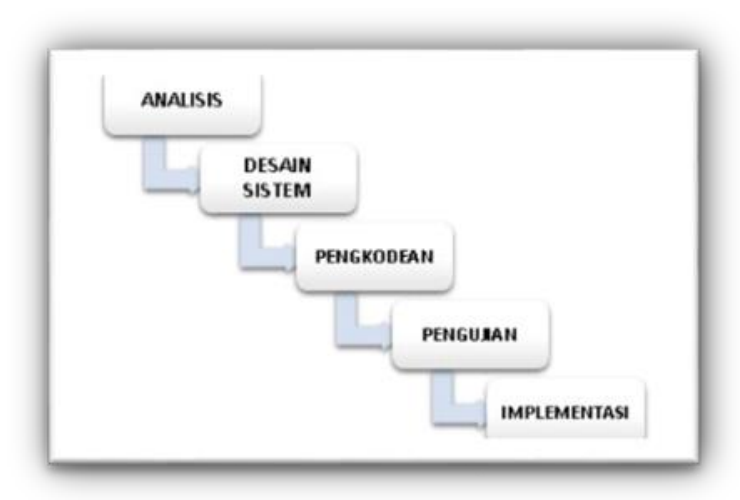

Dalam analisis dilakukan observasi dan wawancara dengan pihak marketing dari PT. Asuransi Tri Pakarta cabang Malang, yang meliputi:

a. Macam-macam produk asuransi kendaraan yang disediakan.

b. Masalah yang sering dialami calon nasabah.

c. Kriteria dalam memilih asuransi kendaraan.

2. Desain Sistem

Dalam desain sistem dilakukan perancangan desain sistem yang akan diterapkan pada sistem rekomendasi asuransi kendaraan dengan menggunakan Unified Modeling Language yang terdiri dari use case diagram, sub use case, activity diagram, sequence diagram dan class diagram.

3. Pengkodean

Dalam tahap pengkodean ini mengacu pada desain sistem, desain sistem di implementasikan menggunakan bahasa pemrograman PHP. Software yang digunakan untuk penulisan kode menggunakan teks editor sublime text.

4. Pengujian

Langkah ini merupakan tahapan dimana sistem akan diuji kemampuan dan keefektifanya sehingga dapat mengetahui kekurangan dan kelemahan sistem yang kemudian akan dilakukan perbaikan sistem sehingga sistem yang dikembangkan menjadi lebih baik.

5. Implementasi

Langkah ini merupakan tahapan dimana dilakukan implementasi sistem ke pengguna, cara penggunaan sistem, pemeliharaan sistem secara berkala, evaluasi sistem agar sistem dapat tetap berjalan dan berkembang sesuai dengan fungsinya.

\section{B. Black Box Testing}

1. Metode black box testing memfokuskan pada keperluan fungsional dari sistem yang dibuat. Uji coba black box testing memungkinkan pengembang sistem untuk membuat himpunan kondisi input yang akan menguji seluruh fungsi-fungsi dari suatu program. Black box testing bukan solusi alternatif dari white box testing tapi sebagai pelengkap untuk menguji sistem dari beberapa hal yang tidak dicakup oleh white box testing (Mustaqbal, Firdaus, \& Rahmadi, 2015).

\section{HASIL DAN PEMBAHASAN}

\section{A. Analisis}

Dalam tahapan ini dilakukan observasi dan wawancara dengan mengajukan pertanyaan mengenai kebutuhan sistem yang dibutuhkan. Setelah tahapan observasi dan wawancara dilakukan tahapan ini juga menghasilkan tabel kebutuhan hardware dan software sesuai kebutuhan perusahaan.

\section{B. Desain Sistem}

Dalam tahap ini dilakukan perancangan desain sistem menggunakan Unified Modeling Language yang terdiri dari use case diagram, sub use case, deskripsi sub use case, actifity diagram, squence diagram dan class diagram. 


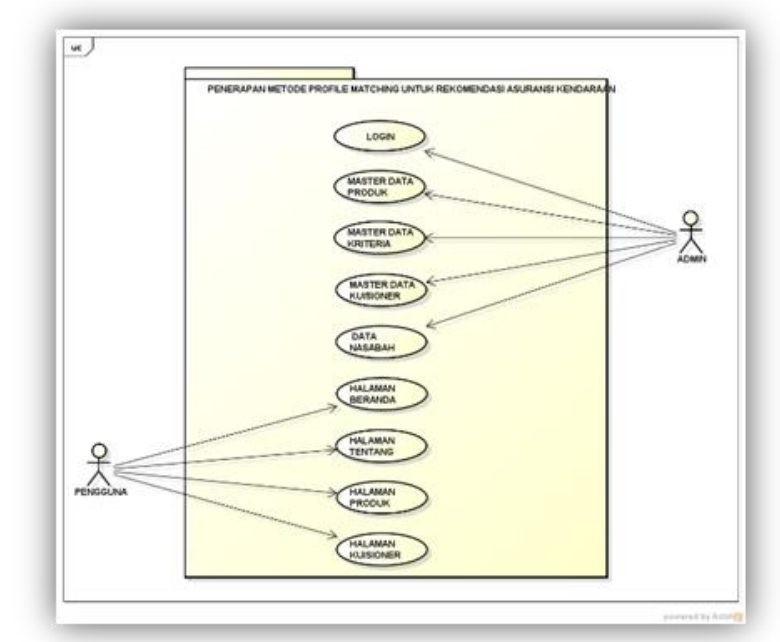

Gambar 2 Use Case Diagram Utama

Pada Gambar 2 terdapat dua aktor pengguna sistem, aktor yang pertama adalah admin yang mengelolah database pada backend sistem. Actor yang kedua adalah pengguna atau calon nasabah asuransi yang mengakses frontend sistem.

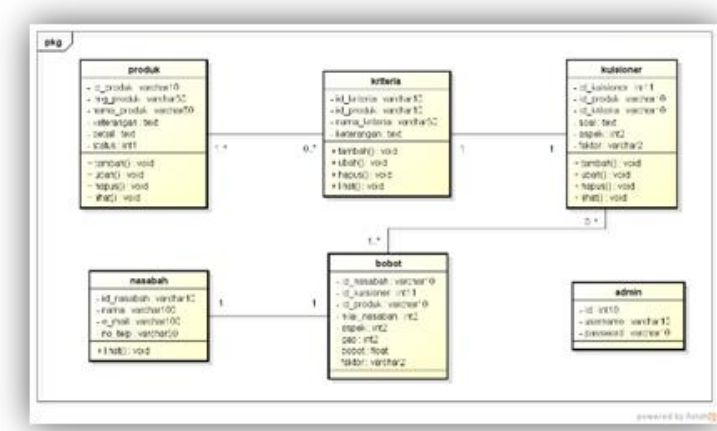

Gambar 3 Class Diagram

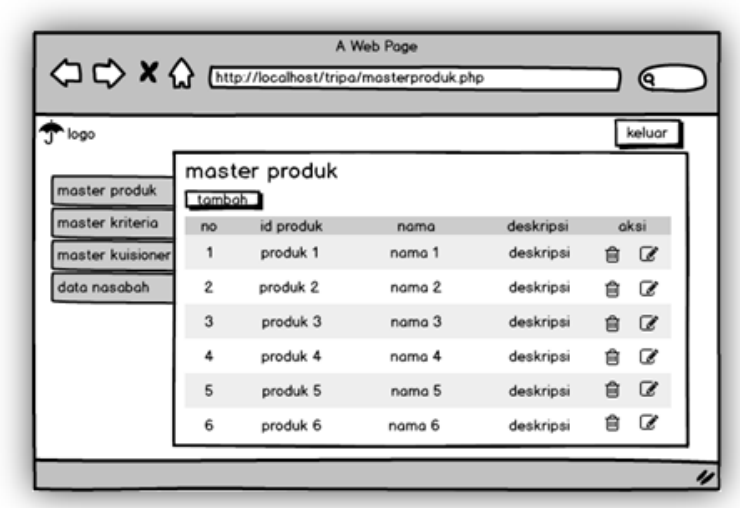

Gambar 4 Desain GUI Back-end Sistem 


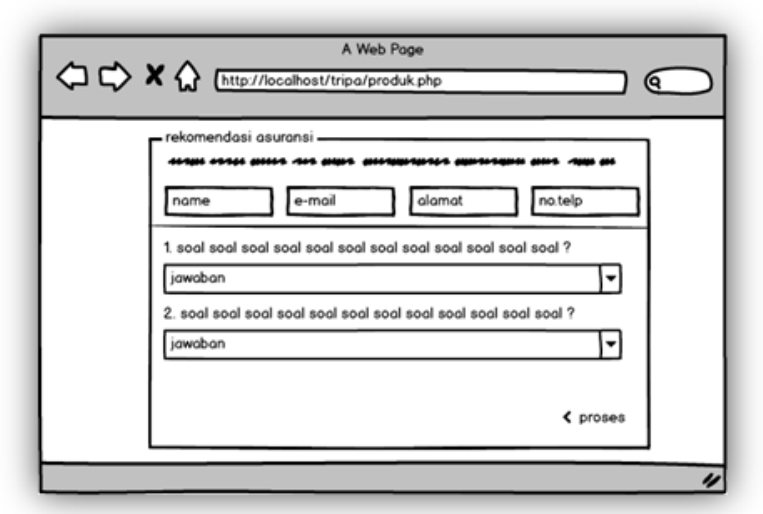

\section{Pengkodean}

\section{Gambar 5 Desain GUI Front-end Sistem}

Pada tahap pengkodean program dilakukan penulisan kode program menyesuaikan hasil dari tahapan desain produk. Tahapan dalam pemrograman yaitu mengimlementasikan hasil rancangan ke dalam baris kode dan tampilan sistem yang berjalan sesuai dengan fungsinya.

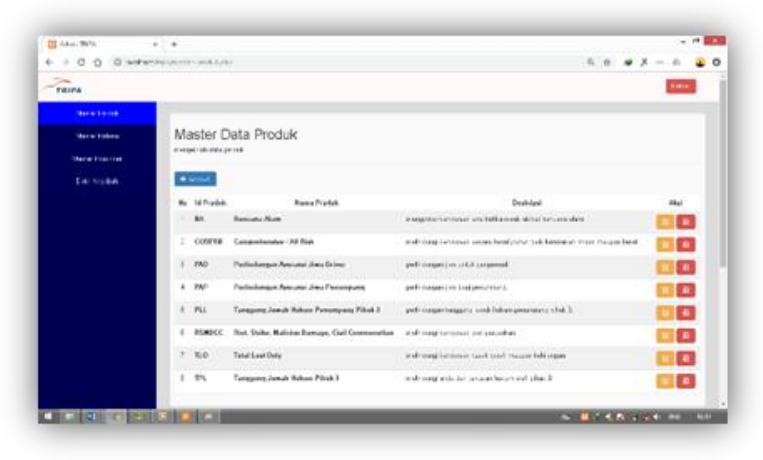

Gambar 6 User Interface Back-end Sistem

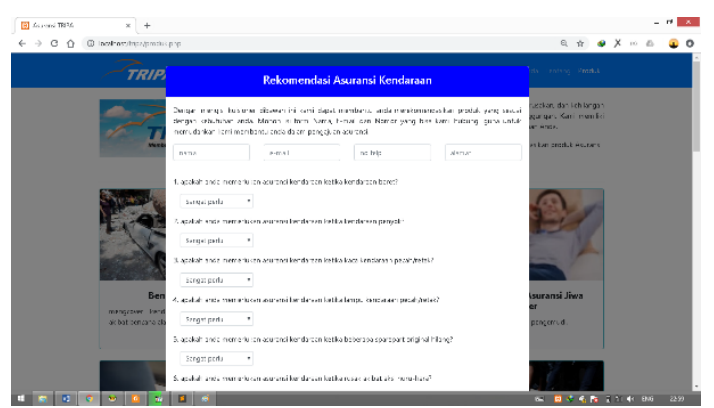

Gambar 7 User Interface Front-end Sistem

\section{Pengujian}

Dalam tahapan pengujian sistem ini dilakukan untuk menguji kemampuan dan keefektifan dari sistem sistem yang telah dibuat. Pengujian sistem diuji menggunakan black box testing dan user acceptance test (UAT).

\section{Tabel 1 Black Box Testing}

Kode Testing ; UCBL1

Deskripsi : Admin memilih menu master kuisioner dan sistem menampilkan list data kuisioner, kemudian admin dapat melakukan tambah data, edit dan hapus kemudian simpan data kusioner ke database.

\begin{tabular}{cccccc}
\hline No & $\begin{array}{c}\text { Fungsi yang } \\
\text { Diuji }\end{array}$ & $\begin{array}{c}\text { Skenario } \\
\text { Pengujian }\end{array}$ & $\begin{array}{c}\text { Hasil yang } \\
\text { Diharapkan }\end{array}$ & Hasil Pengujian & Keterangan \\
\hline \multicolumn{5}{c}{ Sukses } \\
\hline 1 & Mastering & Tambah data & Sistem sukses input & Sistem sukses input & Sesuai
\end{tabular}




\begin{tabular}{|c|c|c|c|c|c|}
\hline & $\begin{array}{l}\text { data kuisioner } \\
\text { (tambah data) }\end{array}$ & $\begin{array}{l}\text { kuisioner dan } \\
\text { simpan (tidak ada } \\
\text { form yang } \\
\text { kosong) lalu tekan } \\
\text { tombol simpan }\end{array}$ & data & $\begin{array}{l}\text { data dan } \\
\text { menyimpan data } \\
\text { kuisioner di } \\
\text { database }\end{array}$ & \\
\hline 2 & $\begin{array}{l}\text { Mastering } \\
\text { data kuisioner } \\
\text { (Edit data) }\end{array}$ & $\begin{array}{l}\text { Sistem dapat } \\
\text { melakukan proses } \\
\text { edit data kuisioner } \\
\text { dengan memilih } \\
\text { menu edit. }\end{array}$ & $\begin{array}{l}\text { Sistem akan } \\
\text { menampilkan form } \\
\text { edit data. }\end{array}$ & $\begin{array}{l}\text { Sistem } \\
\text { menampilkan form } \\
\text { edit dan isi sesuai } \\
\text { ketentuan lalu tekan } \\
\text { simpan dan } \\
\text { menyimpan data di } \\
\text { database }\end{array}$ & Sesuai \\
\hline 3 & $\begin{array}{l}\text { Mastering } \\
\text { data kuisioner } \\
\text { (Hapus data) }\end{array}$ & $\begin{array}{l}\text { Sistem dapat } \\
\text { melakukan hapus } \\
\text { data kuisioner }\end{array}$ & $\begin{array}{l}\text { Sistem akan } \\
\text { menampilkan } \\
\text { notifikasi hapus } \\
\text { data }\end{array}$ & $\begin{array}{l}\text { Sistem } \\
\text { menampilkan } \\
\text { notifikasi hapus } \\
\text { data }\end{array}$ & Sesuai \\
\hline \multicolumn{6}{|c|}{ Gagal } \\
\hline 4 & $\begin{array}{l}\text { Mastering } \\
\text { data kuisioner } \\
\text { (tambah data } \\
\text { tidak lengkap) }\end{array}$ & $\begin{array}{l}\text { Tambah data } \\
\text { kuisioner (data } \\
\text { yang diinput tidak } \\
\text { lengkap), lalu klik } \\
\text { tombol simpan. }\end{array}$ & $\begin{array}{l}\text { Sistem tidak akan } \\
\text { menyimpan ketika } \\
\text { form tidak terisi } \\
\text { semua dan } \\
\text { menampilkan pesan } \\
\text { "harap isi bidang } \\
\text { ini". }\end{array}$ & $\begin{array}{l}\text { Muncul notifikasi } \\
\text { pada sistem dengan } \\
\text { keterangan "harap } \\
\text { isi bidang ini". }\end{array}$ & Sesuai \\
\hline 5 & $\begin{array}{l}\text { Mastering } \\
\text { data kuisioner } \\
\text { (edit data } \\
\text { tidak lengkap) }\end{array}$ & $\begin{array}{l}\text { Edit data kusioner } \\
\text { (data yang diinput } \\
\text { tidak lengkap), } \\
\text { lalu klik tombol } \\
\text { simpan. }\end{array}$ & $\begin{array}{l}\text { Sistem tidak akan } \\
\text { menyimpan ketika } \\
\text { form tidak terisi } \\
\text { semua dan } \\
\text { menampilkan pesan } \\
\text { "harap isi bidang } \\
\text { ini". }\end{array}$ & $\begin{array}{l}\text { Muncul notifikasi } \\
\text { pada sistem dengan } \\
\text { keterangan "harap } \\
\text { isi bidang ini". }\end{array}$ & Sesuai \\
\hline
\end{tabular}

Tabel 2 Pertanyaan dan Jawaban User Acceptance Test

\begin{tabular}{|c|c|c|c|c|c|}
\hline \multirow{2}{*}{ No } & \multirow{2}{*}{ Pertanyaan } & \multicolumn{4}{|c|}{ Jawaban } \\
\hline & & $\mathbf{A}$ & B & $\mathbf{C}$ & D \\
\hline \multicolumn{6}{|c|}{ Aspek Sistem } \\
\hline 1 & Apakah tampilan sistem rekomendasi produk asuransi kendaraan ini menarik? & 8 & 20 & 2 & 0 \\
\hline 2 & $\begin{array}{l}\text { Apakah tampilan warna dan interface pada sistem rekomendasi produk asuransi kendaraan enak dilihat } \& \text { tidak } \\
\text { membosankan? }\end{array}$ & 9 & 19 & 2 & 0 \\
\hline 3 & Apakah sistem rekomendasi produk asuransi kendaraan mudah dioperasikan? & 7 & 20 & 3 & 0 \\
\hline 4 & Apakah evaluasi pada sistem rekomendasi produk asuransi kendaraan ini sudah sesuai dengan silabus? & 6 & 17 & 7 & 0 \\
\hline \multicolumn{6}{|c|}{ Aspek Pengguna } \\
\hline 6 & Apakah materi sistem rekomendasi produk asuransi kendaraan ini mudah dipahami? & 1 & 22 & 7 & 0 \\
\hline 7 & Apakah contoh yang diberikan membantu memahai produk asuransi kendaraan? & 2 & 17 & 11 & 0 \\
\hline 8 & Apakah evaluasi membantu mengukur pemahaman materi produk asuransi kendaraan? & 8 & 21 & 1 & 0 \\
\hline 9 & Apakah sistem rekomendasi produk asuransi kendaraan dapat di akses online? & 1 & 14 & 12 & 3 \\
\hline \multicolumn{6}{|c|}{ Aspek Interaksi } \\
\hline 10 & Apakah mudah dalam mengakses informasi dari semua menu yang diberikan? & 7 & 22 & 1 & 0 \\
\hline 11 & Apakah semua link bekerja secara optimal? & 4 & 22 & 4 & 0 \\
\hline 12 & Apakah soal evaluasi dapat diakses dengan baik? & 1 & 22 & 7 & 0 \\
\hline
\end{tabular}

Prosentase diperoleh dari hasil jawaban responden / jumlah responden kemudian dikali seratus. Setelah melakukan perhitungan prosentase dari data yang didapat, kemudian setiap jawaban dikalikan dengan bobot yang sudah ditentukan. Adapun bobot dari masing - masing jawaban dapat dili hat pada Tabel 3.

Tabel 3 Bobot Jawaban User Acceptance Test

\begin{tabular}{ccc} 
& Tabel 3 Bobot Jawaban User Acceptance Test \\
\hline A & Jawaban & Bobot \\
& Sangat Setuju & 4 \\
\hline
\end{tabular}




\begin{tabular}{lcc}
\hline B & Setuju & 3 \\
C & Kurang Setuju & 2 \\
D & Tidak Setuju & 1 \\
\hline
\end{tabular}

Tabel 4 Prosentase dan Nilai User Acceptance Test

\begin{tabular}{|c|c|c|c|c|c|c|c|c|c|}
\hline \multirow{2}{*}{ No } & \multicolumn{4}{|c|}{ Prosentase } & \multicolumn{4}{|c|}{ Nilai } & \multirow{2}{*}{ Jumlah } \\
\hline & $\mathbf{A}$ & B & C & D & Ax4 & Bx3 & $\mathrm{Cx} 2$ & Dx1 & \\
\hline 2 & $30 \%$ & $63,3 \%$ & $6,7 \%$ & $0 \%$ & 36 & 57 & 4 & 0 & 97 \\
\hline 4 & $20 \%$ & $56,7 \%$ & $23,3 \%$ & $0 \%$ & 24 & 51 & 14 & 0 & 89 \\
\hline 5 & $13,3 \%$ & $73,3 \%$ & $13,3 \%$ & $0 \%$ & 16 & 66 & 8 & 0 & 90 \\
\hline 6 & $3,4 \%$ & $73,3 \%$ & $23,3 \%$ & $0 \%$ & 4 & 66 & 14 & 0 & 84 \\
\hline 9 & $3,3 \%$ & $46,7 \%$ & $40 \%$ & $10 \%$ & 4 & 42 & 24 & 3 & 73 \\
\hline 10 & $23,3 \%$ & $73,3 \%$ & $3,4 \%$ & $0 \%$ & 28 & 66 & 2 & 0 & 96 \\
\hline 11 & $13,3 \%$ & $73,3 \%$ & $13,3 \%$ & $0 \%$ & 16 & 66 & 8 & 0 & 90 \\
\hline 12 & $3,4 \%$ & $73,3 \%$ & $23,3 \%$ & $0 \%$ & 4 & 66 & 14 & 0 & 84 \\
\hline 13 & $6,7 \%$ & $56,7 \%$ & $36,7 \%$ & $0 \%$ & 8 & 51 & 22 & 0 & 81 \\
\hline
\end{tabular}

\section{Analisa Hasil}

1. Analisa pertanyaan pertama dapat dilihat bahwa jumlah nilai dari 30 responden adalah 96 . Nilai rata-ratanya adalah $96 / 30=3,2$. Prosentase nilainya adalah $3,2 / 4 \times 100=80 \%$.

2. Analisa pertanyaan kedua dapat dilihat bahwa jumlah nilai dari 30 responden adalah 97 . Nilai rataratanya adalah $97 / 30=3,3$. Prosentase nilainya adalah 3,3/4 x $100=81 \%$.

3. Analisa pertanyaan ketiga dapat dilihat bahwa jumlah nilai dari 30 responden adalah 94 . Nilai rataratanya adalah $94 / 30=3,1$. Prosentase nilainya adalah $3,1 / 4 \times 100=79 \%$.

4. Analisa pertanyaan keempat dapat dilihat bahwa jumlah nilai dari 30 responden adalah 89 . Nilai rata-ratanya adalah $89 / 30=3$. Prosentase nilainya adalah $3 / 4 \times 100=75 \%$.

5. Analisa pertanyaan kelima dapat dilihat bahwa jumlah nilai dari 30 responden adalah 90 . Nilai rataratanya adalah $90 / 30=3$. Prosentase nilainya adalah $3 / 4 \times 100=75 \%$.

6. Analisa pertanyaan keenam dapat dilihat bahwa jumlah nilai dari 30 responden adalah 84 . Nilai rataratanya adalah $84 / 30=2,8$. Prosentase nilainya adalah $2,8 / 4 \times 100=70 \%$.

7. Analisa pertanyaan ketujuh dapat dilihat bahwa jumlah nilai dari 30 responden adalah 81 . Nilai rataratanya adalah $81 / 30=2,7$. Prosentase nilainya adalah $2,7 / 4 \times 100=67 \%$.

8. Analisa pertanyaan kedelapan dapat dilihat bahwa jumlah nilai dari 30 responden adalah 97. Nilai rata-ratanya adalah $97 / 30=3,3$. Prosentase nilainya adalah 3,3/4 x $100=81 \%$.

9. Analisa pertanyaan kesembilan dapat dilihat bahwa jumlah nilai dari 30 responden adalah 73 . Nilai rata-ratanya adalah $73 / 30=2,4$. Prosentase nilainya adalah $2,4 / 4 \times 100=60 \%$.

10. Analisa pertanyaan kesepuluh dapat dilihat bahwa jumlah nilai dari 30 responden adalah 96 . Nilai rata-ratanya adalah $96 / 30=3,2$. Prosentase nilainya adalah 3,2/4 x $100=80 \%$.

11. Analisa pertanyaan sebelas dapat dilihat bahwa jumlah nilai dari 30 responden adalah 90 . Nilai rataratanya adalah $90 / 30=3$. Prosentase nilainya adalah $3 / 4 \times 100=75 \%$.

12. Analisa pertanyaan duabelas dapat dilihat bahwa jumlah nilai dari 30 responden adalah 84 . Nilai rata-ratanya adalah $84 / 30=2,8$. Prosentase nilainya adalah $2,8 / 4 \times 100=70 \%$.

13. Analisa pertanyaan tigabelas dapat dilihat bahwa jumlah nilai dari 30 responden adalah 81 . Nilai rata-ratanya adalah $81 / 30=2,7$. Prosentase nilainya adalah $2,7 / 4 \times 100=67 \%$.

Tabel 5 Hasil Analisa

\begin{tabular}{|c|c|c|c|c|}
\hline \multirow{2}{*}{ Pertanyaan } & \multicolumn{4}{|c|}{ Nilai } \\
\hline & Jumlah & Jmlh/Resp & $\%$ & AVG \\
\hline \multicolumn{5}{|l|}{ Aspek Sistem } \\
\hline 1 & 96 & 3,2 & $80 \%$ & \multirow{4}{*}{$78,6 \%$} \\
\hline 2 & 97 & 3,3 & $81 \%$ & \\
\hline 3 & 94 & 3,1 & $79 \%$ & \\
\hline 4 & 89 & 3 & $75 \%$ & \\
\hline 5 & 90 & 3 & $75 \%$ & \multirow{5}{*}{$70,6 \%$} \\
\hline 6 & 84 & 2,8 & $70 \%$ & \\
\hline 7 & 81 & 2,7 & $67 \%$ & \\
\hline 8 & 97 & 3,3 & $81 \%$ & \\
\hline 9 & 73 & 2,4 & $60 \%$ & \\
\hline \multicolumn{5}{|l|}{ Aspek Interaksi } \\
\hline 10 & 96 & 3,2 & $80 \%$ & $73 \%$ \\
\hline
\end{tabular}




\begin{tabular}{lrrrr}
11 & 90 & 3 & $75 \%$ & \\
12 & 84 & 2,8 & $70 \%$ & \\
13 & 81 & 2,7 & $67 \%$ & $74,1 \%$ \\
\hline
\end{tabular}

Berdasarkan Tabel 5, didapat nilai rata-rata aspek sistem mencapai 78,6\% yang artinya user interface mudah dipahami oleh pengguna sistem. Pada aspek pengguna didapat nilai ratarata mencapai $70,6 \%$ yang artinya masih perlu adanya pengembangan atau perbaikan lagi dari segi kemudahan pengguna dalam memahami semua fitur yang terdapat dalam sistem. Pada aspek interaksi didapat nilai rata-rata mencapai $73 \%$ yang artinya perlu ada sedikit penjelasan lebih rinci terutama pada bagian hasil nilai rekomendasi agar hasil yang ditampilkan sistem lebih mudah dipahami oleh calon nasabah asuransi.

\section{E. Implementasi}

Pada tahap implementasi dilakukan pemeliharaan sistem secara berkala, evaluasi sistem agar sistem dapat tetap berjalan dan berkembang sesuai dengan kebutuhan dan fungsinya.

\section{PENUTUP}

Berdasarkan hasil penelitian dan uji coba sistem yang sudah dilakukan, dapat diambil kesimpulan bahwa sistem yang dikembangkan dapat memudahkan calon nasabah dalam menentukan produk asuransi kendaraan sesuai dengan kebutuhan calon nasabah dengan menerapkan metode profile matching di PT. Asuransi Tri Pakarta cabang Malang. Hasil uji coba user acceptance test dari orang 30 responden $74,1 \%$ menyatakan setuju bahwa sistem dapat merekomendasikan produk kepada calon nasabah.

\section{DAFTAR PUSTAKA}

Dalimunthe, D. A. (2018, Januari 25). Pertumbuhan Asuransi Kendaraan Diprediksi Bisa Mencapai Dua Digit Tahun Ini. Retrieved from News:

https://kontan.co.id/news/pertumbuhan-asuransi-kendaraan-diprediksi-bisa-mencapaidua-digit-tahun-ini

Kadir, A. (2003). Pengenalan Sistem Informasi. Yogyakarta: Andi Offset.

Mustaqbal, M. S., Firdaus, R. F., \& Rahmadi, H. (2015). Pengujian Aplikasi Menggunakan Black Box Testing Boundary Value Analysis (Studi Kasus : Aplikasi Prediksi Kelulusan SNMPTN). JITTER 